The name protarrhenotoky has been suggested for this condition by Prof. J. B. S. Haldane. Kohl ${ }^{2}$ uses the word 'proterandry' for the fact that males emerge before females. This could, of course, be due to their developing more rapidly. It may be desirable to coin a word meaning that male-producing eggs are laid before female-producing eggs.

The evolutionary consequences are interesting. An abnormal sex-ratio is essential for the kind of socializa. tion that the Hymenoptera have achieved. If protarrhenotoky is primitive, the process of socialization must have involved a change over to the condition where a large number of fertilized eggs are laid before any unfertilized eggs are laid, though, so far as I know, complete protothelytoky (where all female-producing eggs precede all the male-producing) has not been observed to be the rule in any hymenopteran.

S. D. JAYAKAR

Genetics and Biometry Laboratory,

Government of Orissa,

Bhubaneswar-3

Orissa, India.

1 Spurway, H., Dronamraju, K. R., and Jayakar, S. D., Atti Quarto Cong. Intern. U.I.E.I.S., Pavia (in the press).

' Kohl, F. F., Ann. Naturhist. Hofmuseums, 32, 1 (1918). s Olberg, G., Das Verhalten der Solitären Wespen Mitteleuropas (Berlin,

\section{Resistance to the Cabbage Aphid (Brevicoryne brassicae) in Brassica Plants}

A MARROW-STEM kale (Brassica oleracea var. acephala) selection segregated on selfing for plants with and without cuticular wax on their leaves, and it was observed in a natural field infestation that the non-waxy plants were not colonized by the cabbage aphid (Brevicoryne brassicae L.), whereas the normal, waxy plants had large colonies. The resistance of non-waxy plants was confirmed in a field plot, artificially infested. In a severe attack of cabbage white fly (Aleuroides brassicae Walk.), which developed later in the year than the aphid attack, no larvæ or pupæ, and only occasional adult flies, were found on the non-waxy plants, whereas the lower sides of the leaves of the waxy plants were covered with white fly at all stages of their life-cycle.

The non-waxy plants were thus resistant to both cabbage aphid and white fly. Both insects secrete a white, mealy covering of wax over their bodies, and it therefore seems possible that the absence of wax or its immediate precursors in the plants may be the cause of the resistance. In brussels sprouts (var. gemmifera) and in other botanical varieties of $B$. oleracea, waxes and related substances are present as an integral part of the cell cytoplasm as well as forming cuticular wax ${ }^{1}$.

Other factors, besides non-waxiness, may be involved in resistance to cabbage aphids. Thus Wensler ${ }^{2}$ found that the mustard oil glucoside, sinigrin, is a specific stimulus for host selection by $B$. brassicae. A.lso lines of kale, with some resistance to aphids but not with waxless leaves, can be bred. It may be that such lines have a low sinigrin content.

Differences in waxiness of plants also occur between species in the genus Brassica and may be correlated with relative susceptibility to cabbage aphids. Heatheote ${ }^{3}$ found the aphid to flourish best on brussels sprouts with cauliflower ( $B$. oleracea var. botrytis) and cabbage ( $B$. oleracea var. capitata) as other good hosts, and Lamb ${ }^{4}$ found dwarf Essex rape (B. napus L.) to be very susceptible, marrow-stem kale to be fairly susceptible and turnips (B. rapa L.) to be resistant. Both the B. oleracea varieties (brussels sprouts, cauliflower, cabbage and kale) and $B$. napus have waxy, blue green leaves, whereas turnips (B. rapa) have light green leaves with less wax. A.lso it is known that turnips contain sinigrin because their leaves were attractive in Wensler's experiments.
Qualitative as well as quantitative differences in cytoplasmic wax contents might also be of some importance. Chibnall and Piper ${ }^{1}$ found $B$. oleracea varieties and $B$. napus to contain either 15-nonacosanone $\left(\mathrm{C}_{2 \mathrm{\rho}} \mathrm{H}_{58} \mathrm{O}\right)$ or 15-nonacosanol, the ketone and alcohol from $n$-nonacosan. While both were present in brussels sprouts, neither were identified in white mustard (Sinapis alba L.), which is known to be fairly resistant to eabbage aphids.

It would thus appear that, although sinigrin may be a specific stimulus for host selection by the cabbage aphid, resistance to the aphid can be determined by the waxy or non-waxy nature of Brassica plants.

Plant Breeding Institute,

\section{K. F. ThOMPSON}

Maris Lane,

Trumpington,

Cambridge.

${ }^{x}$ Chibnall, A. C., and Piper, S. H., Biochem. J., 28, 2209 (1934).

${ }^{2}$ Wensler, R. J. D., Nature, 195, 830 (1962).

${ }^{3}$ Heatheote, G. D., thesis, Univ. London (1955) cited in Broadbent, $\mathbf{L}$.' Investigation of Virus Diseases of Brassica Crops (Camb. Univ. Press). ‘ Lamb, K. P., N.Z. J. Agric. Res., 3, 320 (1960).

\section{Differential Utilization of Amino-acids by Myzus persicae (Sulzer) fed on Artificial Diets}

IN a recent report by Mittler and $\operatorname{Dadd}^{1}$ on the artificial feeding of Myzus persicae (Sulzer) through membranes of stretched 'Parafilm' it was noted that the aphids excreted numerous honeydew droplets when feeding on an 18 per cent sucrose solution with or without amino-acids, vitamins and salts.

Spot tests failed to detect amino-acids in the honeydew excreted by $M$. persicae feeding on solutions of sucrose only, but indicated a high level of amino-compounds in the honeydew excreted by aphids feeding on a diet containing the $20 \mathrm{~L}$-amino-acids previously listed ${ }^{x}$.

In order to test whether some of these dietary aminoacids are differentially utilized by the aphids, 20 per cent sucrose solutions containing only 3 or 6 of the 20 aminoacids, at the concentrations indicated in Table 1, were fed to several groups of $40-90$ apterous adult $M$. persicae for periods of 6 days and the honeydew excreted by each group analysed chromatographically. Five of the amino-acids were selected from those considered to be essential in the nutrition of several insects ${ }^{2}$ and hence likely to be required in specific amounts also by aphids, whereas asparagine was included as it is frequently a major component of plant sap. A butanol-methyl ethyl ketone-water solvent ${ }^{3}$ was found to give good and rapid resolution on strip chromatograms of the 6 amino-acids. From diet honeydew comparisons the relative amounts of the excreted amino-acids were semi-quantitatively evaluated (Table 1).

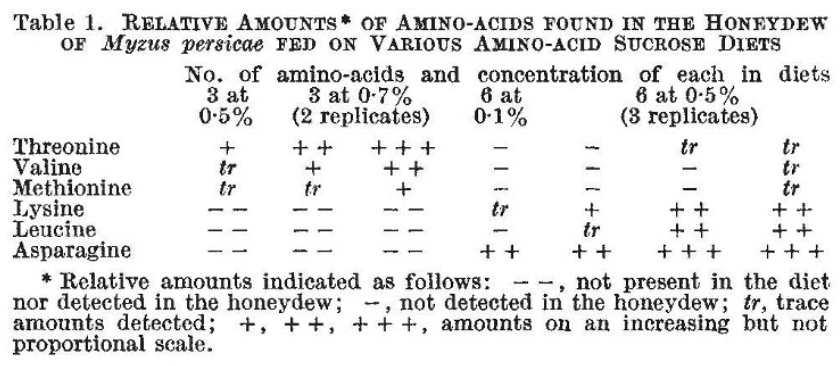

It is evident that the 6 amino-acids were not excreted in the same proportions as they occurred in the diets. The amino-acids could be arranged in the following order in which they were found to occur in progressively decreasing amounts in the honoydew: asparagine, lysine, leucine, threonine, valine and methionine. The chromatograms also indicated that as the amino-acid concentrations in the diets are increased the number and concentration 